have been for a length of time involved in a cicatrix, or where the nerve is itself a seat of disease; but the cases are as yet too few to generalise upon, and we must await the experience to be gained from fuller trial.

\section{A CASE OF NON-TROPICAL CHYLURIA.}

Read before the International Medical Congress, Berlin, August, 1890.

BY W. H. MYERS, M.D., Fort Wayne, Ind., U.S.A.

THE case reported in this paper is intended as a contribution to the literature of chyluria of non-tropical origin. In Winter's Clinical and Practical Pathology occurs a "chyluria urine," which is extremely rarely met with except in those who bave resided in the tropics. Tyson alludes to only three cases, reported as non-tropical. A. B. Buchanan, of Glasgow, in the recital of a case, found by research three examples recorded as ocsurring in temperate latitudes.

Miss W., aged 27, of Scotch descent; a healthy child until she was 11 years. old. At this period she began to complain of pain on the outer aspect of the left thigh. The symptoms were like those of sciatica, and she was treated for this disease at intervals until she was 16; she was then placed under the care of Dr. Livingstone, of New York. A seton was inserted in the upper portion of the left thigh, and during the operation a milky fluid was seen to escape from the wound in considerable quantity.

At that time the limb was larger than the right; notably was this the case after fatigue, following active exercise. Twenty or more small prominences, vesicular in character, were located upon the inner and outer aspects of the upper portion of the left thigh, and from them a discharge from day to day occurred. This liquid, upon chemical analysis, proved to be chyle, the quantity variable, but largely augmented after dancing or long walks, and then often amounting to ten or twelve ounces. This, followed by languor and anorexia, compelled the patient to remain in bed for a few days. The above is the history of the case until within a comparatively recent period, when, after an illness of several months' duration (not under my observation), a new phase presented itself. The fluid from the vesicles ceased entirely, and chylous urine since then has been passed in large quantities daily, micturition being impeded at times owing to the presence of coagula formed in the bladder, blocking up the urethra. These were excessive in quantity, and greatly influenced by exercise.

At such times a chill is present, low temperature, pain in the back, mental depr ssion, and extreme restlessness, followed by accelerated pulse, and slight increase of temperature. The urine, if allowed to ramain in the vessel for a short time, became semi-solid owing to coagulation, and presented a pinkish appearance, owing to the presence of blood.

I sent a recent specimen to Drs. J. Reeve Jackson and Perdy, of Chicago, and the following was the report: Color, milky; transparency greatly diminished; specific gravity, 1,020; reaction, neutral; amount in 24 hours, 3 to 4 pounds.

Chemical Examination.-Urine contains chyle in large amount transparency of urine returns after shaking with anhydrous ether. The urine contains albumin sereral grains to the litre, and a trace of urea.

Organised Deposit.-Consists of granules and some blood corpuscles. No renal casts present.

Unorganised Deposit.-A few crystals of triple phosphate present.

I will add that after repeated microscopic examinations of the blood taken at that period in the twenty-four hours when filario are usually discovered, I have failed to detect their presence. Toat there is deeply-seated local hypertrophy and irritation of the lymphatic system, I have no doubt.

I do not believe the theory, advanced by Dr. Ellison and advocated by Drs. Reid and Bird, that it is renal ; the evidence in this case is entirely wanting. I think with Dr. Carter that by distension of the delicate lymphatics and lacteals in the lumbar region a rupture has taken place, and a fistulous orifice remains which gives free exit to the chyle or lymph at times of greatest distension; since the urine solidifies and takes on a reddish tinge on exposure to the air, or contains clots at the time of expulsion, we may suppose that the communication is placed high up, communicating with the larger lacteals or thoracic duct itself.
Dr. Sausurie, of Charleston, South Carolina, has reported 28 cases quite recently, and the question now presents itself for our consideration whether those cases indicate that the filaria sangrinis hominis is about to invade a region hitherto exempt.

\section{THE TREATMENT OF INTERNAL DERANGE-} MENTS OF THE KNEE-JOINT BY OPERATION.

By EDWARD BELLAMY, F.R.C.S., Surgeon to Charing Cross Hospital.

I HAVE been very much interested in Mr. Herbert Allingham's work on this subject. He has forestalled me, in so far that $I$ thought of suggesting as a datum this clearly "unwritten" chapter in surgery some years ago, when, as teacher of anatomy, I carried out Bonnet's experiments on joints ; and further, I injected joints with wax and plaster with the idea of getting at the anomalies and irregularities of their internal arrangements, and a mathematical attempt at the "capacities of joint areas." The results were very interesting. I obtained hardly any precise similarity in the contouring of the "casts I made. Of course, from my material, the specimens were often in some pathological condition; but even in those supposed to be anatomically perfect I was much struck with the variation in the relation of the "folds," "ligamenta alaria," "pouches," and " distensions," so different from the figures in the then textbooks.

Of course Bonnet's experiments all know of, and in my translation of Braune they are given in detail. I think my experiments were of use, as in later surgical experience, on examining the interiors of joints with "the clean aseptic finger," I was able to detect conditions I originally came across almost at hap hazard in the dissecting room. I am, of course, more particularly speaking of the knee, though I may safely speak of other large joint cavities. The comparison of this great joint cavity anatomically and its treatment surgically as compared with the other great serous cavities I long ago taught and acted upon, and there may be some analogy between these deran zements in the joint and those of the peritoneum.

I have used this free aseptic "sweep" round for a great many cases, and have never had any bad result as yet. The expression "mysterious improvement" sounds possibly somewhat empirical, but it is nevertheless a happy one, though the results want explanation. My own opinion is that the finger breaks down some trabeculæ or detaches some fringes or loose cartilages, for example.

I recenlly (with Dr. Birch, of Tretower Road) saw a very muscular gentleman, who, some years back, had "ricked" the knee at some athletic sports. He had suffered pain of a very severe character for some time past, and Dr. Birch and I thought we could detect a loose cartilage beneath the patella. There was great pain in moving the patella, and a most distinct creak could be heard and felt on doing so. Under ether, I made a free antiseptic incision on the outer side of the knee, opening the synovial membrane. I passed my forefinger beneath the patella, and with my finger-nail detached what felt like a cartilaginous growth; but which I failed to extract; it had clearly got displaced into the surrounding tissues. I washed the joint out, put in a few horsehair stitches, and placed the limb on a splint. The wound healed very quickly, and he has got well without any bad symptoms.

In consultation with Dr. C. A. Smith, of Yonge Park, Finsbury, I operated on a lady, who since childhood-she is about 35 years of age-had had a neglected, deformed, and painful condition of the knee-owing I suppose to the usual female reticence of consulting anyone until necessary, she went on suffering. At any rate, we detected "loose cartilages" on the inner aspect of the patella, feeling exactly like a couple of shillings. A free aseptic incision soon removed her trouble and set her at ease. Here, again, the internal aspect of the synovial cavity was freely "swept" round, and I detected numerous tightenings and entanglements of the membrane-possibly acquired, possibly original.

I could quote several others, but these are quite recent. It is worthy of notice that in "erasion" of the synovial membraneof the knee, say-the difficulty of the procedure of removal lies along the primitive points or areas of adhẹsion. 